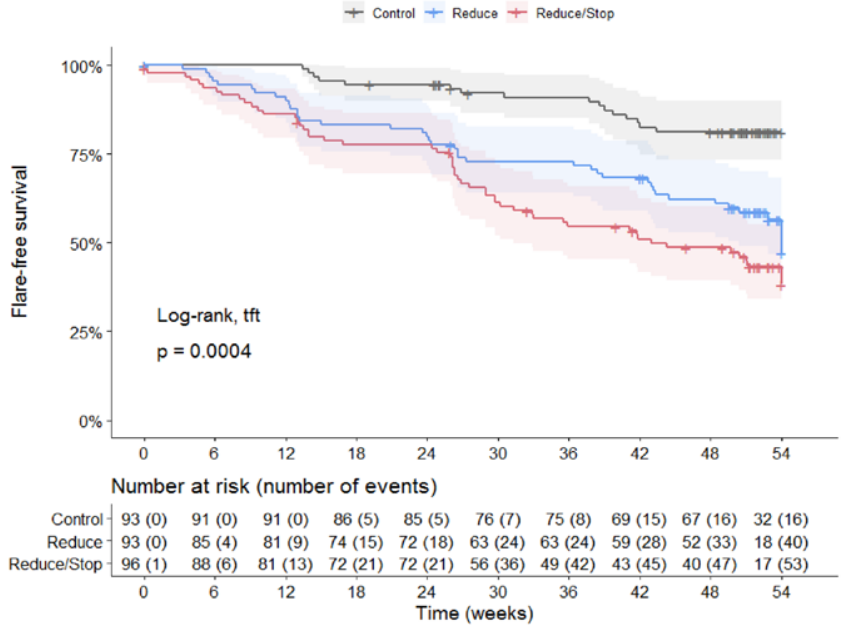

REFERENCES:

[1] Schett $\mathrm{G}$ et al. Tapering biologic and conventional DMARD therapy in rheumatoid arthritis: current evidence and future directions. Ann Rheum Dis. 2016 Aug;75(8):1428-37.

Disclosure of Interests: Melanie Hagen Speakers bureau: advisory boards, Koray Tascilar Speakers bureau: advisory board, Michaela Reiser: None declared, Larissa Valor: None declared, Judith Haschka Speakers bureau: advisory board, Arnd Kleyer Speakers bureau: advisory board, Axel Hueber Speakers bureau: advisory boards, Bernhard Manger Speakers bureau: advisory boards, Jayme Cobra Speakers bureau: advisory boards, Camille Figuereido Speakers bureau: advisory boards, Stephanie Finzel Speakers bureau: advisory boards, Hans-Peter Tony Speakers bureau: advisory boards, Joerg Wendler Speakers bureau: advisory boards, Stefan Kleinert Speakers bureau: advisory boards, Florian Schuch Speakers bureau: advisory boards, Monika Ronneberger: None declared, Martin Feuchtenberger Speakers bureau: advisory boards, Martin Fleck Speakers bureau: advisory boards, Karin Manger: None declared, Wolfgang Ochs: None declared, Matthias SchmittHaendle: None declared, Hanns-Martin Lorenz Speakers bureau: advisory boards, Rieke Alten Speakers bureau: advisory boards, Jörg Henes Speakers bureau: advisory boards, Klaus Krueger Speakers bureau: advisory boards, Jürgen Rech Speakers bureau: advisory boards, Georg Schett Speakers bureau: advisory boards.

DOI: 10.1136/annrheumdis-2021-eular.2174

\section{OP0319 OSTEOSARCOPENIA INCREASES THE RISK OF FALLS IN PATIENTS WITH RHEUMATOID ARTHRITIS: RESULTS OF A FOUR-YEAR LONGITUDINAL STUDY}

M. Tada ${ }^{1}$, Y. Yamada ${ }^{2}$, K. Mandai ${ }^{3}$, N. Hidaka ${ }^{1}{ }^{1}$ Osaka City General Hospital, Orthopaedic Surgery, Osaka, Japan; ${ }^{2}$ Osaka City University Medical School, Orthopaedic Surgery, Osaka, Japan; ${ }^{3}$ Osaka Saiseikai Nakatsu Hospital, Orthopaedic Surgery, Osaka, Japan

Background: Osteosarcopenia is defined as osteoporosis combined with sarcopenia. Both osteoporosis and sarcopenia are risk factors for falls and fractures in healthy individuals ${ }^{1}$. The relationships of falls and fractures to osteosarcopenia in rheumatoid arthritis (RA) patients are unknown.

Objectives: The synergistic effect of osteoporosis and sarcopenia and the impact of osteosarcopenia on falls and fractures in RA patients were investigated using four years of data from a longitudinal study.

Methods: The data from a prospective, observational study (CHIKARA study: UMIN000023744) were examined. The patients were divided into four groups according to their baseline status: no sarcopenia and osteoporosis (SP-OP-); only sarcopenia (SP+OP-); only osteoporosis (SP-OP+); and both sarcopenia and osteoporosis $(\mathrm{SP}+\mathrm{OP}+)$. Sarcopenia was diagnosed by the criteria of the Asia Working Group on Sarcopenia $2014^{2}$. Patients with osteoporosis were defined as those having a therapeutic intervention for osteoporosis. The survival rate and Cox hazard ratio were analyzed using falls and fractures as endpoints, adjusted by age, sex, and body mass index.
Results: A total of 100 RA patients (female $78 \%$, mean age 66.1 years) were enrolled. The number of SP-OP-, SP+OP-, SP-OP+, and SP+OP+ patients was $45,17,27$, and 11 , respectively. Their baseline characteristics are shown in Table 1. A total of 35 patients had falls, and 19 patients had fractures during the four-year follow-up. The fall-free survival rate in the SP-OP-, SP+OP-, $\mathrm{SP}-\mathrm{OP}+$, and $\mathrm{SP}+\mathrm{OP}+$ groups was $75.6 \%, 64.7 \%, 51.9 \%$, and $36.4 \%$, respectively; that of the $\mathrm{SP}+\mathrm{OP}+$ group was significantly lower than that the other groups $(P=0.021)$ (Figure 1). The fracture-free survival rate in the SP-OP-, SP+OP-, SP-OP+, and SP+OP+ groups was $86.7 \%, 82.4 \%, 81.5 \%$, and $54.5 \%$, respectively. That of the $\mathrm{SP}+\mathrm{OP}+$ group was relatively lower than that of the other groups $(\mathrm{P}=0.121)$. The hazard ratio of falls was significantly increased in the SP+OP+ group by 3.32 -fold $(95 \% \mathrm{Cl}: 1.01-10.9)$ compared to that in the SP-OP- group, whereas that in the SP+OP- and SP-OP+ groups was 2.58 -fold (95\% Cl: $0.75-8.8)$ and 2.29 -fold $(95 \% \mathrm{Cl}$ : 0.94-5.6) higher, respectively. There were no significant differences compared to the SP-OPgroup. The hazard ratio of fractures in the $\mathrm{SP}+\mathrm{OP}+$ group was increased 2.73-fold (95\%Cl: 0.61-12.2) compared to that in the SP-OP- group.

Table 1. Baseline characteristics of the four groups

\begin{tabular}{|c|c|c|c|c|c|}
\hline & SA-OP- & $\mathrm{SA}+\mathrm{OP}-$ & $\mathrm{SA}-\mathrm{OP}+$ & $\mathrm{SA}+\mathrm{OP}+$ & $\begin{array}{l}P \\
\text { value }^{*}\end{array}$ \\
\hline Female, \% & 73.3 & 58.8 & 88.9 & 100 & 0.027 \\
\hline Age, years & $63(49,72)$ & $69(60,79)$ & $73(64,75)$ & $73(65,81)$ & 0.008 \\
\hline $\begin{array}{l}\text { Disease duration, } \\
\text { years }\end{array}$ & $4.4(1.0,8.4)$ & $4.0(1.3,8.9)$ & $7.6(1.5,14.5)$ & $10.5(3.2,26.5)$ & 5) 0.035 \\
\hline DAS28-ESR & $\begin{array}{l}3.14(2.66 \\
3.70)\end{array}$ & $3.55(3.01,4.65)$ & $\begin{array}{l}3.93(3.28, \\
4.63)\end{array}$ & $\begin{array}{l}3.53(2.48, \\
3.89)\end{array}$ & 0.01 \\
\hline $\mathrm{mHAQ}$ & $0.25(0,0.375)$ & $\begin{array}{l}0.375(0.125 \\
0.875)\end{array}$ & $\begin{array}{l}0.375(0.125, \\
0.875)\end{array}$ & $\begin{array}{l}0.5(0.125 \\
0.875)\end{array}$ & 0.065 \\
\hline $\begin{array}{l}\text { MTX, mg/week, } \\
\text { rate (\%) }\end{array}$ & $\begin{array}{l}8.4 \pm 2.9 \\
(86.7)\end{array}$ & $8.7 \pm 3.5(70.6)$ & $8.3 \pm 2.8(92.6)$ & $6.8 \pm 1.0(90.9)$ & 9) 0.388 \\
\hline $\begin{array}{l}\text { Glucocorticoid, mg/ } \\
\text { day, rate (\%) }\end{array}$ & $3.7 \pm 1.9(20.0)$ & $6.3 \pm 1.8(11.8)$ & $4.0 \pm 1.7(44.4)$ & $3.8 \pm 1.8$ & 2) 0.400 \\
\hline $\begin{array}{l}\text { Body mass index, } \\
\mathrm{kg} / \mathrm{m}^{2}\end{array}$ & $23.4 \pm 3.8$ & $19.2 \pm 2.3$ & $21.7 \pm 2.4$ & $19.2 \pm 2.0$ & $<0.001$ \\
\hline
\end{tabular}

Data are shown as mean \pm standard deviation (SD) or median (25th, 75th percentile).* : compared in four groups by Kruskal-Walls test.

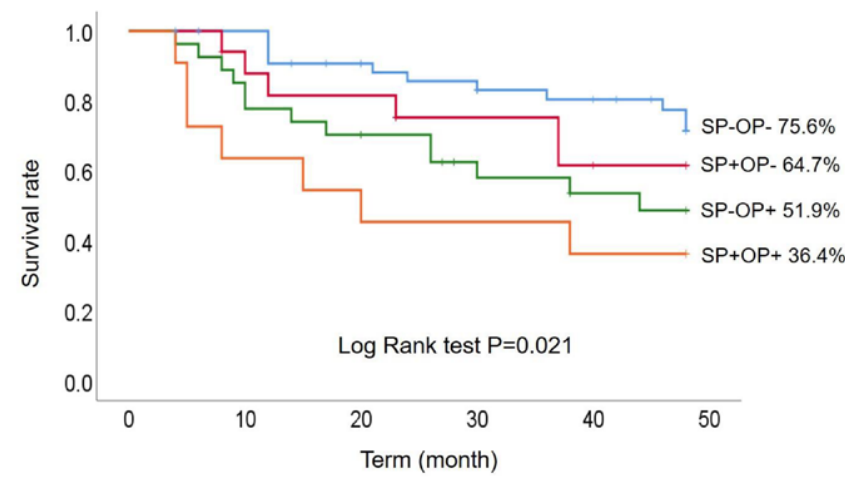

Figure 1. Fall-free survival rates of the four groups.

Conclusion: The survival rates with the endpoints of falls and fractures in RA patients with osteosarcopenia were lower during the four-year follow-up. In particular, the risk of falls increased with the synergistic effect of osteoporosis and sarcopenia in RA patients.

\section{REFERENCES:}

[1] Dennison, E. M. et al. Fracture risk following intermission of osteoporosis therapy. Osteoporos Int 30, 1733-1743, doi:10.1007/s00198-019-05002-w (2019).

[2] Chen, L. K. et al. Sarcopenia in Asia: consensus report of the Asian Work ing Group for Sarcopenia. J Am Med Dir Assoc 15, 95-101, doi:10.1016/j. jamda.2013.11.025 (2014).

Disclosure of Interests: None declared.

DOI: 10.1136/annrheumdis-2021-eular.942 